\title{
May Circulating Steroids Reveal a Predisposition to Intrahepatic Cholestasis of Pregnancy in Non-Pregnant Women?
}

\author{
P. ŠIMJÁK ${ }^{1}$, M. HILL ${ }^{2}$, A. PAŘÍZEK ${ }^{1}$, L. VÍTEK ${ }^{3}$, M. VELÍKOVÁ ${ }^{2}$, M. DUŠKOVÁ ${ }^{2}$, \\ R. KANCHEVA ${ }^{2}$, J. BULANT ${ }^{2,4}$, M. KOUCKÝ ${ }^{1}$, Z. KOKRDOVÁ ${ }^{1}$, K. ADAMCOVÁ ${ }^{1}$, \\ A. ČERNÝ ${ }^{1}$, Z. HÁJEK ${ }^{1}$, L. STÁRKA ${ }^{2}$
}

${ }^{1}$ Department of Gynecology and Obstetrics, General University Hospital and First Faculty of Medicine, Charles University in Prague, Czech Republic, ${ }^{2}$ Institute of Endocrinology, Prague, Czech Republic, ${ }^{3}$ Institute of Medical Biochemistry and Laboratory Diagnostics and Fourth Department of Internal Medicine, General University Hospital and First Faculty of Medicine of Charles University in Prague, Czech Republic, ${ }^{4}$ Department of Pediatrics and Adolescent Medicine, General University Hospital and First Faculty of Medicine of Charles University in Prague, Czech Republic

Received August 28, 2018

Accepted September 14, 2018

\begin{abstract}
Summary
Intrahepatic cholestasis of pregnancy (ICP) is a frequent liver disorder, mostly occurring in the third trimester. ICP is not harmful to the mothers but threatens the fetus. The authors evaluated steroid alterations in maternal and mixed umbilical blood to elucidate their role in the ICP development. Ten women with ICP were included in the study. Steroids in the maternal blood were measured by Gas Chromatography-Mass Spectrometry (GC-MS) $(n=58)$ and RIA $(n=5)$ at the diagnosis of ICP, labor, day 5 postpartum, week 3 postpartum and week 6 postpartum. The results were evaluated by ANOVA consisting of the subject factor, between subject factors ICP, gestational age at the diagnosis of ICP and gestational age at labor, withinsubject factor Stage and ICP $\times$ Stage interaction. The 17 controls were firstly examined in the week 36 of gestation. ICP patients showed reduced CYP17A1 activity in the C17,20 lyase step thus shifting the balance between the toxic conjugated pregnanediols and harmless sulfated $5 a / \beta$-reduced-17-oxo C19 steroids. Hence, more toxic metabolites originating in maternal liver from the placental pregnanes may penetrate backward to the fetal circulation. As these alterations persist in puerperium, the circulating steroids could be potentially used for predicting the predisposition to ICP even before next pregnancy.
\end{abstract}

\section{Key words}

Intrahepatic cholestasis of pregnancy • Liver enzymes • Steroid metabolism • Gas chromatography-mass spectrometry $\bullet$ Prediction

\section{Corresponding author}

M. Hill, Department of Steroids and Proteohormones, Institute of Endocrinology, Národní 8, 116 94, Prague, 116 94, Czech Republic. E-mail: mhill@endo.cz

\section{Introduction}

Intrahepatic cholestasis of pregnancy (ICP) is the most frequent liver disorder in pregnancy. The disease is associated with an altered biliary secretion of bile acids (BA) and other biliary lipids and usually induces placental oxidative stress and apoptosis. Although ICP is associated with a discomfort in pregnant women, it does not seriously harm them. Instead, ICP represents a serious risk and difficult-to-predict complications in the fetus including preterm birth, meconium flux into the amniotic fluid, respiratory distress syndrome, and sudden intrauterine fetal death (Simjak et al. 2014). The risk of ICP rises with escalating levels of pregnancy steroids during the third trimester of pregnancy. Furthermore, the risk of ICP is higher in multiple pregnancies with multiple sources of fetal steroid precursors such as sulfated C21 and C19 $\Delta^{5}$ steroids (Parizek et al. 2015). These steroid sulfates enter the placenta, which desulfates them and converts the unconjugated steroids to progestogens and estrogens. Placental progestogens may be converted to their $5 \alpha$-reduced metabolites and, after 
entering the maternal circulation, these substances may be subsequently sulfated and/or glucuronized in the maternal liver. As we have previously reported, the conjugation of $5 \alpha / \beta$-reduced-20-oxo-pregnanes in the maternal compartment increases with the approaching term (Hill et al. 2010a). During enterohepatic circulation, both progesterone and estrogen metabolites may be transformed into cholestatic compounds (Reyes 2008). Although the maternal liver plays a key role in the catabolism of maternal progesterone, the formation and catabolism of female sex hormones is not limited to the maternal liver, ovaries, and adrenals. There is a bidirectional flux to the fetal-placental unit and the fetal adrenal and placenta synthesize a substantial part of the substrates for the production of active hormones and consequently their noxious catabolites. About half of the progesterone metabolism occurs in extrahepatic sites (Hill et al. 2010a, Reyes 2016). In ICP patients, the sulfated progesterone catabolites are increased 4-10 times when compared with healthy pregnant women, while glucuronidated metabolites remain unaffected by either pregnancy or ICP. The patients also show an increased ratio of $3 \alpha$ - to $3 \beta$-hydroxysteroid sulfates in serum (Reyes 2016). ICP symptoms withdraw shortly after birth as the placental conversion of fetal steroids disappears, and the activity of the fetal adrenal zone declines (Glantz et al. 2008, Lammert et al. 2000).

ICP is probably associated with an overproduction of sulfated progesterone metabolites such as pregnanolone isomers and pregnanediols and the pathophysiology of ICP may be influenced by enzymes interconverting the $3 \beta$-hydroxy, 3-oxo-, and $3 \alpha$-hydroxypregnanes and by selective defect in steroid sulfate conjugation affecting the biliary secretion of steroid metabolites (Glantz et al. 2008, Meng et al. 1997). The key role of progesterone catabolism in the pathophysiology of ICP is also shown by reduced progesterone levels and elevated concentrations of its metabolites in women with asymptomatic hypercholanemia, which is accompanied by moderately elevated total bile acids (TBA) $(>11 \mu \mathrm{M})$ but normal aminotransferases (Pascual et al. 2002). The increased levels of sulfated pregnanediols may also predict the ICP onset (Abu-Hayyeh et al. 2016, Parizek et al. 2016) and the overproduction of conjugated progesterone catabolite isopregnanolone ( $3 \beta, 5 \alpha$-THP) sulfate inhibits the de novo synthesis of hepatic farnesoid X receptor (FXR), which may result in a cholestatic phenotype (Abu-Hayyeh et al. 2013, Rizzo et al. 2005). Data from animal models reveal that estradiol and reduced pregnane steroids inhibit the bile salt export pump (BSEP), which is responsible for bile acids (BAs) secretion while the progesterone itself is inactive (Byrne et al. 2002, Vallejo et al. 2006).

In the mild ICP, some reports indicate that the fetuses of mothers with ICP have elevated circulating cortisol and dehydroepiandrosterone sulfate (DHEAS) probably due to increased activity of both the maternal zona fasciculata and zona reticularis. However, in severe ICP, there is a suppressed stress response system (Wang et al. 2011) and other authors record lower levels of DHEAS and estrogens in women with ICP (Leslie et al. 2000).

Although the aforementioned data indicate an important role for steroids in the pathophysiology of ICP, there is still a number of questions to be addressed. In our previous study, we evaluated the differences between maternal circulating steroids in women with ICP before the beginning of the therapy by ursodeoxycholic acid (UDCA) to assess potential importance of maternal circulating steroids for the diagnosis of ICP (Parizek et al. 2016). Here we followed the time profiles of maternal circulating steroids from late pregnancy to week 6 postpartum to explain the associations of individual steps of steroid metabolism (during pregnancy, at labor and in postpartum period) with the etiopathogenesis of ICP to examine whether the steroidogenesis in patients remains altered in the postpartum period. This may be helpful for the discovery of potential markers of ICP predisposition in non-pregnant women.

\section{Methods}

\section{Subjects}

Ten pregnant women with ICP were included in the study. The mean gestational age at the onset of ICP was $35.8 \pm 1.7$ weeks (range 29-38). All women with ICP had increased TBA levels $(\geq 8 \mu \mathrm{mol} / 1), 90 \%$ of them exhibited elevated aminotransferases and half of them suffered from pruritus. Other causes of cholestasis were excluded by detailed clinical and laboratory examinations. Four cases of severe ICP (TBA $>40 \mu \mathrm{mol} / \mathrm{l})$ were recorded. All pregnancies were singleton. Gestational diabetes mellitus was an exclusion criterion for both controls and patients. The control group consisted of 17 women with uncomplicated singleton pregnancies, who underwent laboratory examination in the week 36 of pregnancy. No case of maternal pruritus was recorded and serum aminotransferase activities and 
TBA were normal in all controls. At delivery, the mean gestational age of patients with ICP and controls was $37.5 \pm 0.7$ and $39.4 \pm 1.1$ weeks, respectively. Pregnancy ended prematurely in one case of ICP (10\%), whereas in the control group no case of delivery before 37 weeks of pregnancy occurred. From the total of ICP-complicated pregnancies, $40 \%$ were terminated by cesarean section, in contrast to $35 \%$ in the control group. The mean APGAR score at the first minute was $9.3 \pm 0.6$ and $9.2 \pm 0.8$, and at the fifth minute was $10.0 \pm 0.0$ and $9.7 \pm 0.5$ for the ICP and control groups, respectively. From the ICP patients, 7 were treated with $750-1000 \mathrm{mg}$ UDCA/day for 3-14 days after the first blood collection (stage "Dg") and 3 patients did not use UDCA. The Ethics Committee of the General University Hospital and $1^{\text {st }}$ Faculty of Medicine of Charles University in Prague approved this study. Written informed consent was obtained from all study participants before any study related procedures had been carried on.

\section{Sample collection}

In the ICP patients, the blood samples were firstly collected in the $3^{\text {rd }}$ trimester after diagnosis of ICP and before starting the treatment with UDCA while the controls were firstly examined in the week 36 of gestation (stage (Dg)). Both groups were further monitored at labor (Lab), day 5 postpartum (d5), week 3 postpartum (wk3) and week 6 postpartum (wk6). The treatment with UDCA in ICP patients was ceased immediately after labor. Serum was obtained after centrifugation for $5 \mathrm{~min}$ at $2,000 \times \mathrm{g}$ at $0{ }^{\circ} \mathrm{C}$ and stored at $-20^{\circ} \mathrm{C}$ until analyzed.

\section{Liver function tests}

Standard serum biochemical markers such as alanine aminotransferase (ALT), aspartate aminotransferase (AST), $\gamma$-glutamyltransferase (GGT), alkaline phosphatase (ALP) and bilirubin were determined on an automatic analyzer (Modular analyzer, Roche Diagnostics GmbH, Mannheim, Germany), using routine laboratory assays. The TBA were quantified using an EIA kit from Trinity Biotech USA Inc. (Jamestown, NY, USA).

\section{Steroid analysis}

The levels of 38 unconjugated steroids and 25 steroid conjugates were measured in the maternal serum and serum from mixed umbilical blood. The steroid metabolome included C21 $\Delta^{5}$ steroids, C19 $\Delta^{5}$ steroids, C21 $\Delta^{4}$ steroids, C19 $\Delta^{4}$ steroids, estrogens, C21
$5 \alpha / \beta$-reduced steroids and C19 $5 \alpha / \beta$-reduced steroids. Most of the steroids were measured by GC-MS using our previously published method (for details see Hill et al. 2010c). However, instead of the system GCMS-QP2010 Plus we used the GCMS-TQ8040 in this study (both systems were from Shimadzu (Kyoto, Japan)). The analysis was conducted in Q3-SIM mode. 17-hydroxypregnenolone and 17-hydroxypregnenolone sulfate were measured using our previously published RIA methods (Hill et al. 1999, Vcelakova et al. 2007) while 17-hydroxyprogesterone, cortisol, and testosterone were quantified by RIA kits from Immunotech (Marseille, France).

\section{Statistical analysis}

The differences in levels of steroids and liver function test during late gestation, at labor, and during three periods postpartum (day 5 , week 3 , and week 6 postpartum) were evaluated using a mixed-design analysis of variance (ANOVA) model. In this model, the fixed effects factors were between-subjects variables and the stage effect was a within-subjects variable (all subjects were measured in all periods). The betweensubject factors were ICP (ICP positive vs. controls), gestational age at the diagnosis of ICP (GA, Dg: $<$ week 36 vs. $\geq$ week 36 of gestation, samples from controls were collected in week 36 of gestation) and gestational age at labor (GA, labor: <week 38 vs. zweek 38 of gestation). The factors GA, Dg and GA, labor were incorporated into the model to control for changing steroid levels in the fetomaternal circulation during gestation (Hill et al. 2010a, Hill et al. 2014). The within-subject factor was Stage (diagnosis of ICP, labor, day 5 postpartum, week 3 postpartum, week 6 postpartum) and the model also included the ICP $\times$ Stage interaction testing the significance of divergence between time profiles of controls and patients. The mixed-design ANOVA model was followed by least significant difference multiple comparisons. Respecting the skewed data distribution and non-constant variance in most dependent variables, these were transformed by power transformations to achieve data symmetry and homoscedasticity prior to further data processing (Meloun et al. 2000). The homogeneity and distribution of the transformed data were checked by residual analysis as described elsewhere (Meloun et al. 2002). The statistical software Statgraphics Centurion, version XV from Statpoint Inc. (Herndon, Virginia, USA) was used for the ANOVA testing. 

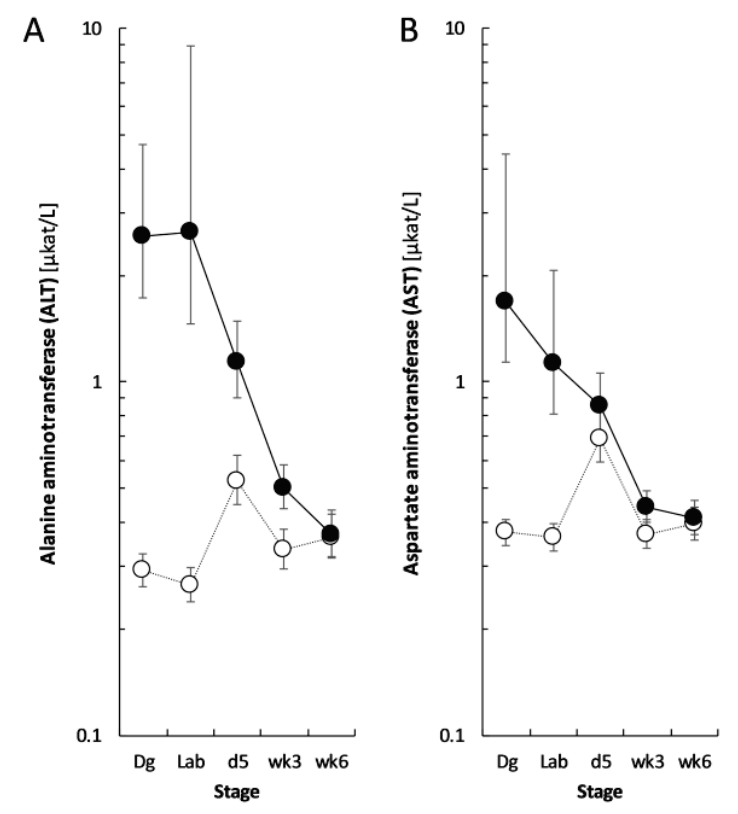

\section{Results}

The profiles of circulating $\mathrm{C} 21$ steroids in women with intrahepatic cholestasis of pregnancy (ICP) and controls (C) at the diagnosis of ICP in the $3^{\text {rd }}$ trimester (Dg), at labor (Lab), day 5 postpartum (d5), week 3 postpartum (wk3) and week 6 postpartum (wk6) are shown in Table 1 as well as the corresponding data for $\mathrm{C} 19$ steroids and estrogens. Liver function tests show pronounced between-group differences in pregnancy, but these differences diminish $\mathrm{d} 5$ and wk3 and disappear in wk6. As expected, all profiles of liver function tests exhibit significant ICP $\times$ Stage interaction demonstrating significantly different courses of the corresponding profiles for controls and patients (Fig. 1). Alternatively, the steroid profiles, as well as ratios of C21 to C19 steroids, keep the between-group differences from stage
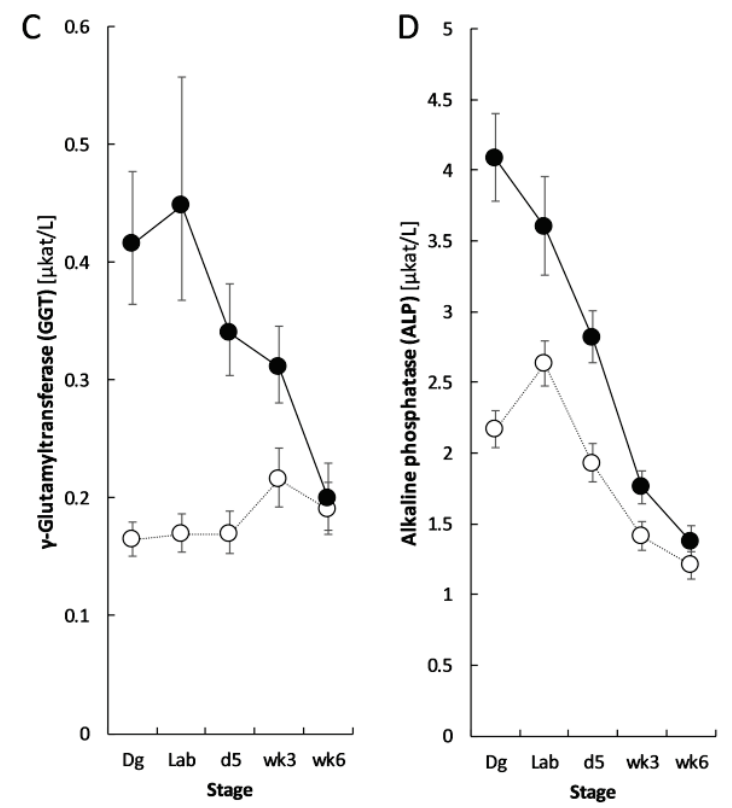

Fig. 1. Profiles of liver function tests in late pregnancy, at labor and postpartum in women with ICP and controls. Full and empty circles with error bars represent the re-transformed means with their $95 \%$ confidence intervals for ICP patients and controls, respectively. The differences in levels of steroids and liver function test during late gestation, at labor, and during three periods postpartum (day 5 , month 3 , and month 6 postpartum) were evaluated using ANOVA model consisting of betweensubject factors ICP (ICP positive vs. controls), gestational age at the diagnosis of ICP (GA, Dg: <week 36 vs. $\geq$ week 36 of gestation, samples from controls were collected in week 36 of gestation) and gestational age at labor (GA, labor: <week 38 vs. $\geq$ week 38 of gestation), within-subject factor Stage and ICP $\times$ Stage interaction. Respecting the skewed data distribution and non-constant variance in most dependent variables, these were transformed by power transformations to achieve data symmetry and homoscedasticity prior to further data processing. Statistical significance of the factors and interaction was as follows: A) ICP: $F=115.5, p<0.001$; Stage: $F=15.2, p<0.001$; ICP $\times$ Stage: $F=22.3, \quad p<0.001 ; \quad$ B) ICP: $F=51.4, \quad p<0.001$; ICP $\times$ Stage: $F=14.4, \quad p<0.001 ; \quad C) \quad$ ICP: $F=90.5, p<0.001$; ICP $\times$ Stage: $F=9.8, \quad p<0.001 ; \quad D) \quad$ ICP: $F=77.4, p<0.001$; ICP $\times$ Stage: $F=8.7, p<0.001$.

Dg up to stage wk6 postpartum (Table 1, Figs 2 and 3 ).
Only the profile of conjugated $5 \alpha$-pregnane- $3 \alpha, 20 \alpha$-diol shows a significant interaction ICP $\times$ Stage indicating different courses of time profiles for ICP group and controls (steeper fall within stages Lab and wk6 in the patients, Table 1). While the levels of C21 steroids tend to higher levels in the patients, the concentrations of $\mathrm{C} 19$ steroids are mostly lower (Table 1, Fig. 2) in this group. Moreover, several profiles of $\mathrm{C} 21$ to $\mathrm{C} 19$ steroid ratios are also regularly shifted to higher values in the patients when compared to controls (Fig. 3). Estrogen profiles mostly do not significantly differ except the levels of estrone sulfate showing a significant shift to lower values and estriol sulfate levels showing the opposite trend (Table 1). In the mixed umbilical blood of ICP patients, we found higher levels of pregnenolone, conjugated and unconjugated $5 \alpha$-pregnane-3 $3,20 \alpha$-diol and cortisol but lower levels of androgen metabolites epiandrosterone, etiocholanolone sulfate and estrogens estrone and estradiol sulfate (Table 2).

\section{Discussion}

In contrast to the liver function tests showing divergent time profiles in patients and controls due to fading concentrations of noxious substances in the former group (Fig. 1), the profiles of steroid levels (Table 1, Fig. 2) and steroid ratios (Fig. 3) were less divergent or parallel particularly in sulfated C19 steroids. This may indicate permanently impaired steroidogenesis in women with ICP irrespectively of the pregnancy status and a possible use of the circulating steroids for estimation of predisposition to ICP even in nonpregnant women. 

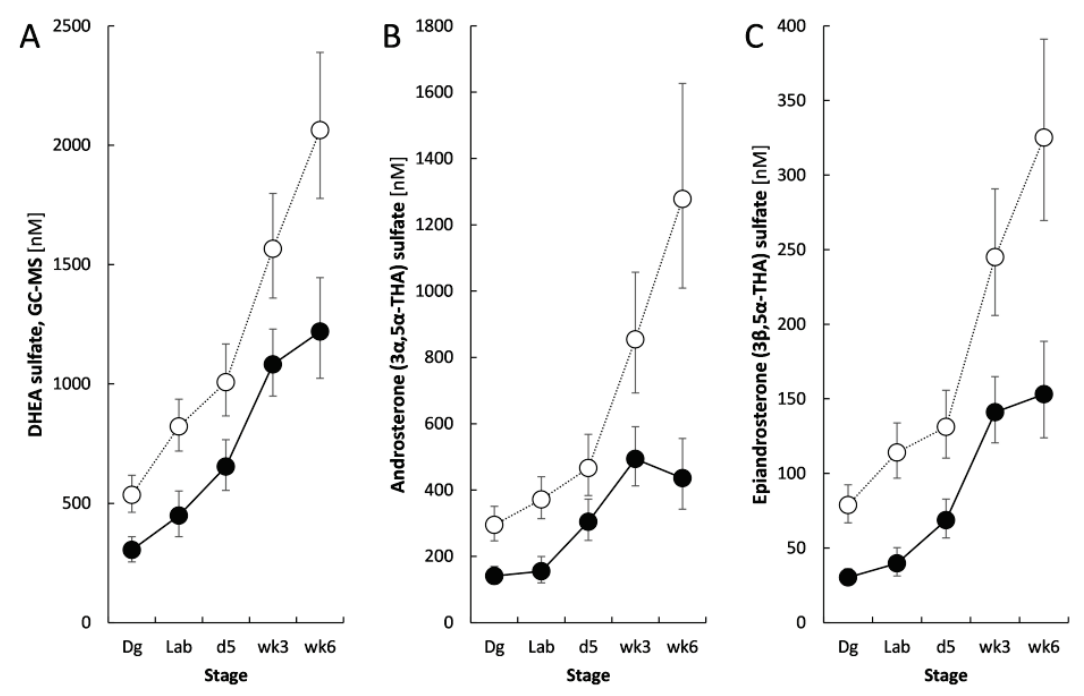

Fig. 2. Profiles of $17-0 x 0-\mathrm{C} 19$ steroids showing significant differences between women with ICP and controls in late pregnancy, at labor and postpartum. The statistical method, symbols, and drawings are the same as for Figure 1. Statistical significance of the factors and interaction was as follows: A) ICP: $F=37.8, \quad p<0.001$; ICP $\times$ Stage: $F=0.3, p=0.876$; B) ICP: $F=47.2, p<0.001 ;$ ICP $\times$ Stage: $F=1.6$, $\mathrm{p}=0.197 ; \mathrm{C})$ ICP: $\mathrm{F}=69.5, \mathrm{p}<0.001$; ICP $\times$ Stage: $F=1.1, p=0.346$; D) ICP: $F=14.1, p<0.001 ;$ ICP $\times$ Stage: $F=0.9$, $p=0.485$; E) ICP: $F=37.2, p<0.001$; ICP $\times$ Stage: $F=1.5, p=0.216$; F) ICP: $F=34.9, p<0.001 ;$ ICP $\times$ Stage: $F=0.9$, $\mathrm{p}=0.463$.
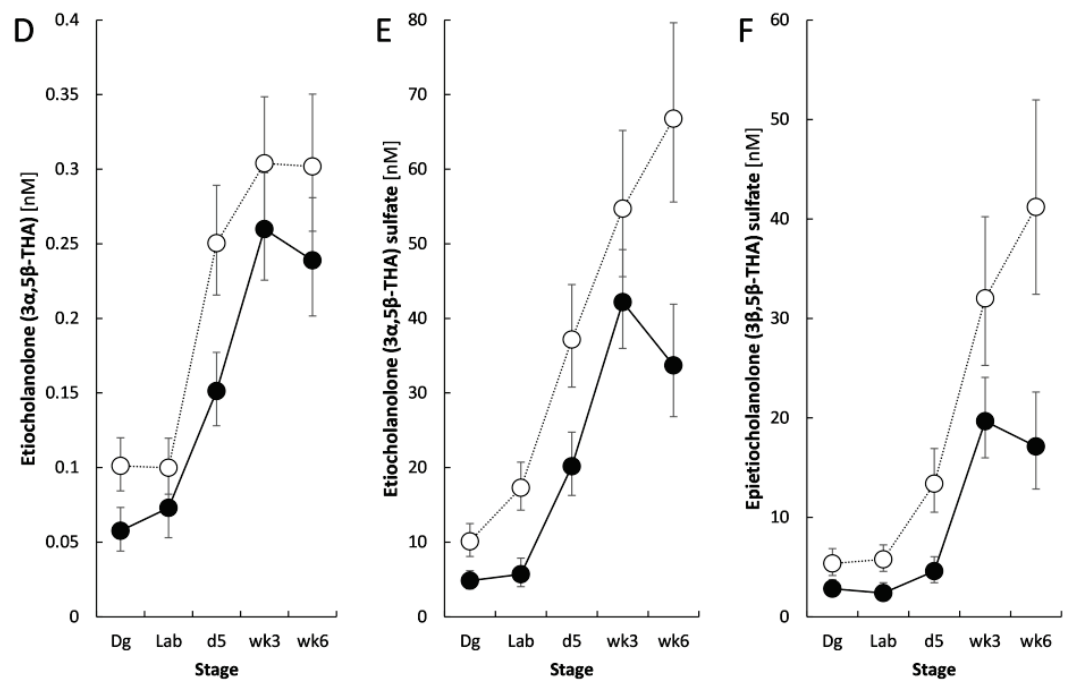

UDCA treatment in most of our ICP-patients after diagnosis of ICP is an important confounding factor for the steroid metabolism between stages Dg and Lab. Nevertheless, the first stage Dg was not influenced by UDCA as the blood withdrawal was performed before the beginning of medication and a similar situation was in postpartum periods when the excessive formation of progesterone was terminated at labor and the UDCA treatment was finished. Concerning the situation after the beginning of UDCA medication to labor, some authors did not found a significant influence of UDCA on steroid metabolism (Estiu et al. 2015) and others reported a suppressed synthesis of $5 \alpha / \beta$-reduced progesterone metabolites (Abu-Hayyeh et al. 2016). In the present study, the levels of $5 \alpha / \beta$-reduced progesterone metabolites at labor remain increased despite the UDCA treatment. The small number of ICP patients untreated by UDCA $(n=3)$ does not allow an exact comparison whether the androgen levels significantly differ between
UDCA-treated and UDCA-untreated ICP patients $(n=7)$ and no data is available in the literature concerning the UDCA effect on conjugated C19 steroids. However, the circulating levels of sulfated androgens in untreated ICP patients at labor are apparently unaltered when compared with the UDCA-treated patients. When considering data from others, the pregnane levels in UDCA-untreated ICP patients would be either unaltered or even higher than in the treated ICP patients (Abu-Hayyeh et al. 2016, Estiu et al. 2015). Therefore, the steroid alterations in the UDCAuntreated ICP patients at labor against the control group would be either comparable or even more explicit than in the case of UDCA-treated women. Thus, our most important finding of permanent alterations in maternal steroidogenesis in ICP patients is not derived from the UDCA treatment but from the predisposition of a part of the female population to ICP due to an attenuated activity of zona reticularis. 


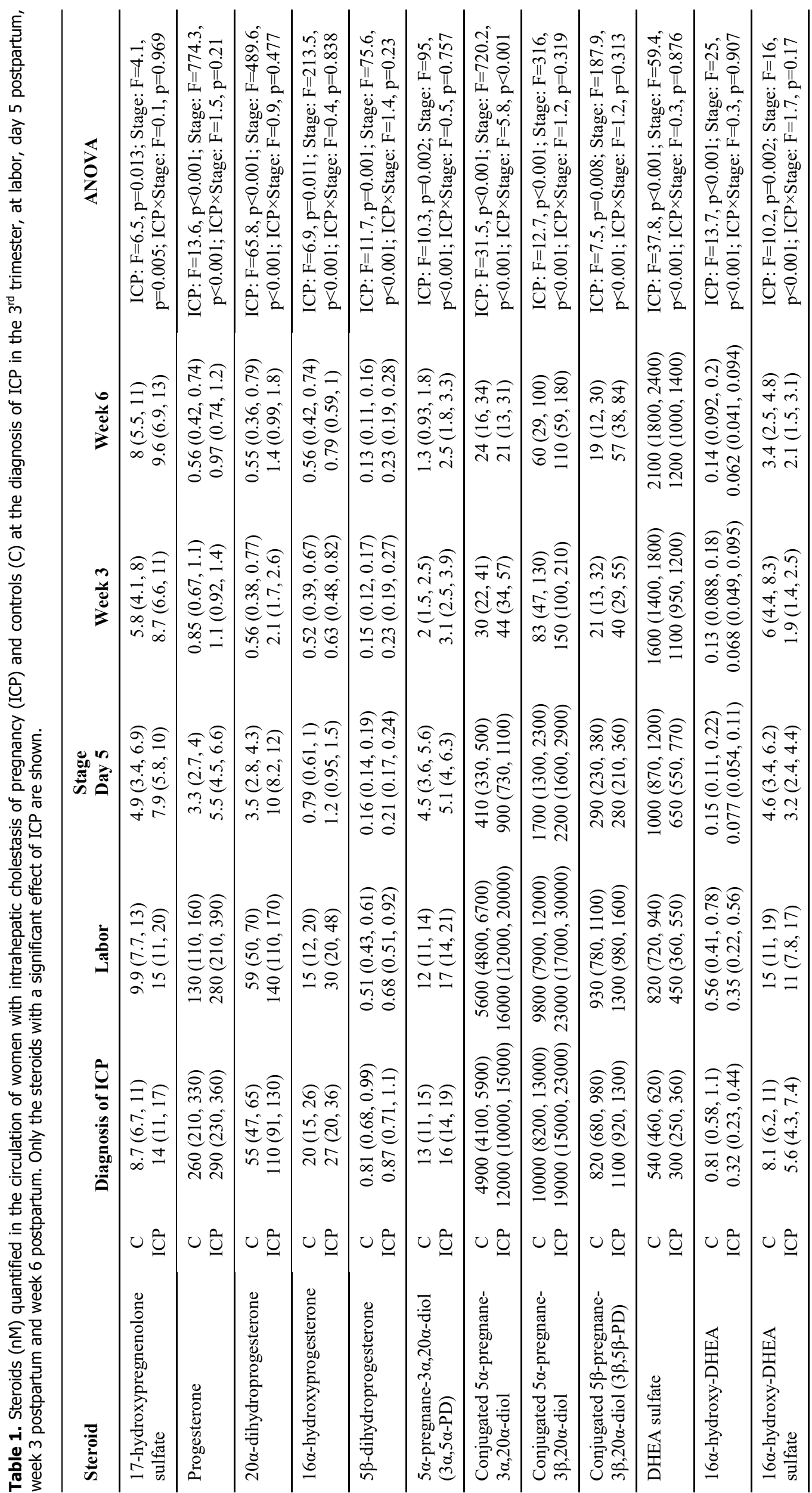




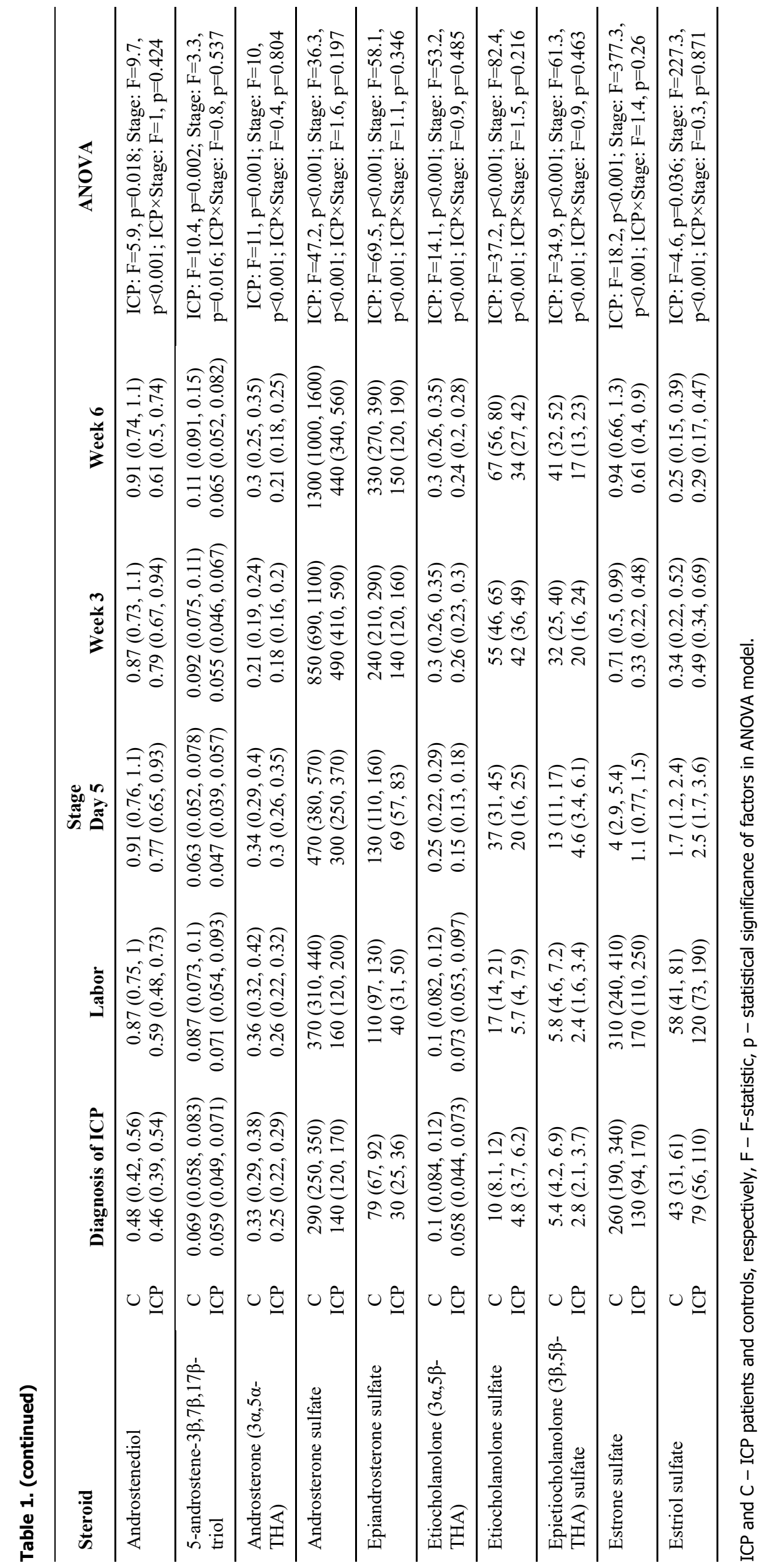


Table 2. Steroids (nM) in mixed umbilical blood from patients with intrahepatic cholestasis of pregnancy (ICP) and controls (C) at labor.

\begin{tabular}{|c|c|c|c|c|}
\hline \multirow{2}{*}{ Variable } & \multicolumn{2}{|c|}{ Group } & \multicolumn{2}{|c|}{ ANOVA } \\
\hline & $\mathbf{C}$ & ICP & $\mathbf{F}$ & $\mathbf{p}$ \\
\hline Pregnenolone & $48(38,63)$ & $31(27,37)$ & 6.7 & 0.018 \\
\hline Cortisol & $280(190,420)$ & $130(100,180)$ & 5.9 & 0.025 \\
\hline Estrone & $130(100,180)$ & $54(40,71)$ & 11 & 0.004 \\
\hline Estradiol sulfate & $7(5.6,8.5)$ & $3.9(3,4.8)$ & 7.9 & 0.011 \\
\hline $5 \alpha$-pregnane- $3 \alpha, 20 \alpha$-diol & $4.27(2.96,5.94)$ & $7.6(5.98,9.55)$ & 4.8 & 0.041 \\
\hline Conjugated $5 \alpha$-pregnane- $3 \alpha, 20 \alpha$-diol & $859(613,1180)$ & $3900(3020,5080)$ & 31.2 & $<0.001$ \\
\hline Epiandrosterone & $0.209(0.157,0.289)$ & $0.132(0.107,0.163)$ & 4.6 & 0.046 \\
\hline Etiocholanolone sulfate & $1.93(1.45,2.53)$ & $0.921(0.709,1.18)$ & 9.2 & 0.007 \\
\hline
\end{tabular}

ICP and C - ICP patients and controls, respectively, F - F-statistic, p - statistical significance of factors in ANOVA model.
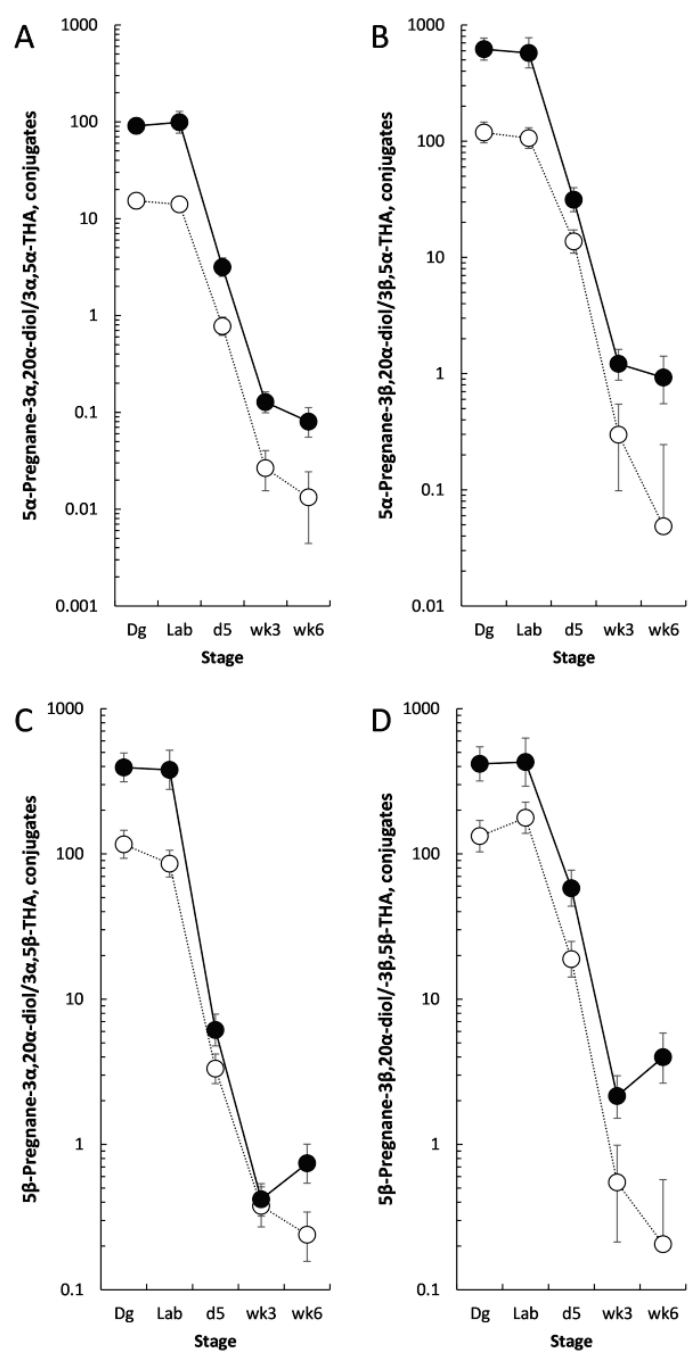

Fig. 3. Profiles of ratios of conjugated pregnanediols to corresponding conjugated $17-0 x 0-5 a / \beta$-reduced androstanes in late pregnancy, at labor and postpartum in women with ICP and controls. The statistical method, symbols, and drawings are the same as for Figure 1. Statistical significance of the factors and interaction was as follows: A) ICP: $F=155.1, \quad p<0.001$; ICP $\times$ Stage: $F=4.6, \quad p=0.002 ; \quad B) \quad I C P: F=84.4, \quad p<0.001$; ICP $\times$ Stage: $F=4.4, \quad p=0.003 ; \quad C) \quad$ ICP: $F=43.4, \quad p<0.001$; ICP $\times$ Stage: $F=5.4, \quad p<0.001 ; \quad$ D) ICP: $F=51.6, \quad p<0.001$; ICP $\times$ Stage: $F=1.1, p=0.346$.
Based on the present results and data from others (Biason-Lauber et al. 2013, Kamrath et al. 2013), we completed a diagram illustrating the formation and transplacental transport of conjugated pregnanediols in pregnancy (Fig. 4). We hypothesize that pregnenolone sulfate of fetal origin is converted to progesterone in placenta and subsequently also to $20 \alpha$-dihydroprogesterone during the transplacental passage. These steroids together with a part of placental progesterone synthesized from the maternal LDL cholesterol (Hill et al. 2010a, Hill et al. 2010b) penetrate into the maternal compartment. Maternal liver and further tissues gradually convert the progestogens to conjugates of pregnanolone isomers and pregnanediols with a shift to the latter substances in ICP patients due to augmented activity of liver AKR1C1 converting steroid 20-oxo- to $20 \alpha$-hydroxy-group. This shift is indicated by more pronounced differences between patients and controls for $20 \alpha$-dihydroprogesterone then for progesterone (Table 1). Pregnanolone isomers and possibly also the pregnanediols are converted to the corresponding $5 \alpha / \beta$-reduced C19 steroids by CYP17A1 via the alternative "backdoor" pathway. Whereas our data indicate reduced CYP17A1 activity for the ICP patients in the $\mathrm{C} 17,20$ lyase step, the balance between the toxic sulfated pregnanediols and harmless $5 \alpha / \beta$-reduced-17-oxo C19 steroids is shifted to the former substances in these patients. Therefore, more quantities of toxic steroid metabolites in ICP patients may penetrate backwards into the fetus. The differences in the mixed umbilical blood are less pronounced than in the maternal blood. However, the main noxa, conjugated $5 \alpha$-pregnane$3 \alpha, 20 \alpha$-diol and its unconjugated counterpart are elevated in the umbilical blood as well. Hence, the altered catabolism of placental steroids in the maternal but not in 
the fetal compartment is critical for the development of ICP. Reduced levels of estrone, estradiol sulfate in the mixed umbilical blood of patients may partly reflect the lower activity of maternal zona reticularis and perhaps also the fetal zone of the fetal adrenal (FZFA) due to hereditary predisposition to lower activities of the aforementioned tissues as estrogens originate from androgens.

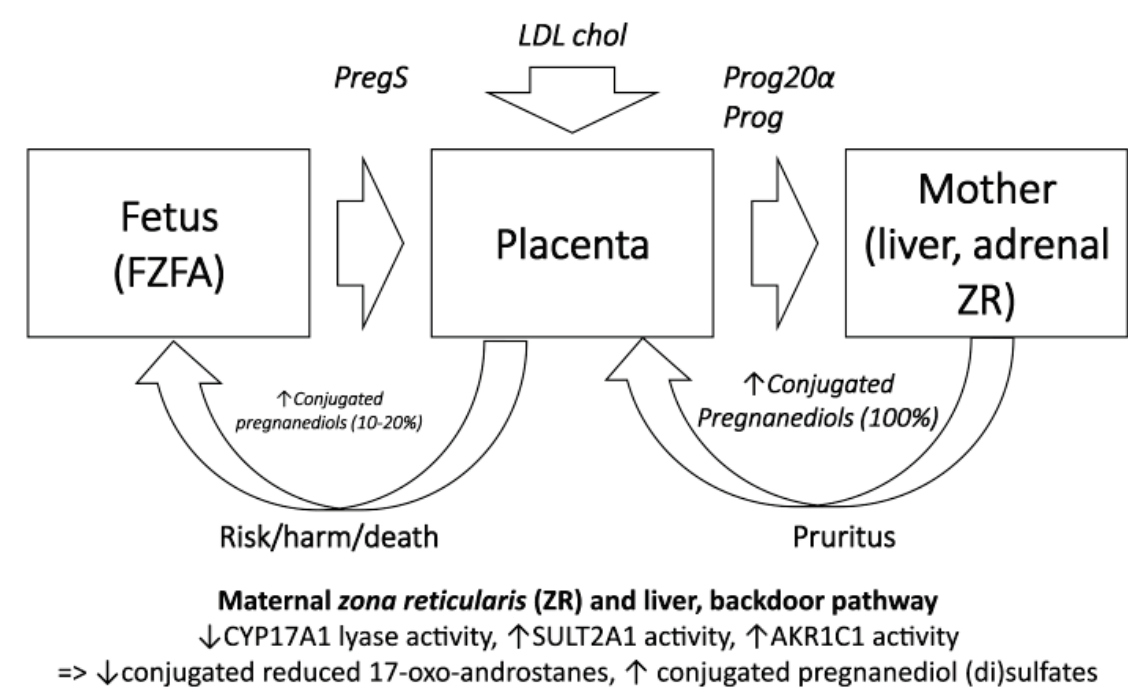

Fig. 4. Simplified scheme of formation and transport of conjugated pregnanediols in pregnancy. FZFA fetal zone of the fetal adrenal, PregS pregnenolone sulfate, LDL chol maternal LDL cholesterol, Prog progesterone, Prog20a - 20adihydroprogesterone, ZR - zona reticularis in maternal adrenal cortex, CYP17A1 - steroid 17-hydroxylase17,20-lyase, SULT2A1 - steroid sulfotransferase, AKR1C1 subfamily1C type 1 aldoketoreductase (20-oxo $\rightarrow$ 20a-hydroxy).

ICP commonly manifests in the third trimester, and the risk of ICP for the fetus increases with increasing gestational age. Moreover, the levels of conjugated pregnanediols also exhibit an increasing trend in this period (Abu-Hayyeh et al. 2016) and then rapidly decrease after labor (Reyes 2016). In humans and great apes, the activity of the FZFA is controlled by the placental corticoliberin (CRH), the expression of which exponentially rises with approaching term (Hill et al. 2010a, Petraglia et al. 2010, Sirianni et al. 2005, Smith et al. 2009). The attenuated activity of CYP17A1 C17,20-lyase step in ICP patients might be associated with a reduced expression of the placental CRH in these subjects as suggested by Zhou et al. (2013). The authors demonstrate lower CRH expression in the placenta from ICP patients with an unchanged placental expression of mRNA for both $\mathrm{CRH}$ and the type $1 \mathrm{CRH}$ receptors (CRH-R1). They also report a considerably slower increase of circulating CRH levels with advancing gestation in the ICP group against controls. Millona et al. (2012) report that BAs strongly inhibit the CYP17A1 expression in mouse liver, which is FXR-dependent. In addition, Anakk et al. (2011) demonstrate that FXR and small heterodimer partner (SHP) knockout mice exhibit strong upregulation of CYP17A1 mRNA, CYP17A1 protein. At the same time, the knockout mice show increased circulating 17-hydroxyprogesterone at suppressed DHEA levels.
The adult zona reticularis is a successor of FZFA and reinstates its functioning from adrenarche reaching maximum activity in the second decade and gradually goes out till senescence (Hill et al. 2010a, Hill et al. 2010b, Rege et al. 2016, Sulcova et al. 1997). We hypothesize, that there is a predisposition to permanently attenuated CYP17A1 activity for the lyase step in women with the history of ICP from adrenarche to senescence irrespectively of the pregnancy status. The reduced activity of CYP17A1 C17,20-lyase step in ICP patients might also be associated with an impaired expression of CYB5 enzyme (Rege et al. 2016) in the maternal zona reticularis. We have also found attenuated activity of the CYP17A1 C17,20 lyase step in further pathologies such as IgA nephropathy (Sterzl et al. 2017), mood and anxiety disorders (Duskova et al. 2015) and Alzheimer's disease (Vankova et al. 2016). This insufficiency was sometimes accompanied by reduced sulfotransferase activity (Vankova et al. 2015).

In conclusion, our results indicate persistent changes in steroid metabolism in women with ICP. Although we do not directly evaluate enzyme activities, but used metabolomic data for their qualitative estimation, the results indicate slightly increased C17-hydroxylation in the steroid $\Delta^{5}$ pathway at pronouncedly weakened $\mathrm{C} 17,20$ lyase step even considering that both steps are catalyzed by the same CYP17A1 enzyme (but on different active sites). 
Whereas the steroid alterations in ICP patients persist in the puerperium, the circulating steroids could be potentially utilized in predicting the predisposition to ICP even in non-pregnant women of fertile age. However, further studies are needed to confirm this hypothesis.

\section{Conflict of Interest}

There is no conflict of interest.

\section{Acknowledgements}

Grants 17-30528A from AZV CR (Czech Health Research Council), OPPK CZ.2.16/3.1.00/21518 Equipment for metabolomics research and the project MZ CR for conceptual development of research organization 00023761 (Institute of Endocrinology, Prague, Czech Republic) supported this study.

\section{References}

ABU-HAYYEH S, PAPACLEOVOULOU G, LOVGREN-SANDBLOM A, TAHIR M, ODUWOLE O, JAMALUDIN NA, RAVAT S, NIKOLOVA V, CHAMBERS J, SELDEN C, REES M, MARSCHALL HU, PARKER MG, WILLIAMSON C: Intrahepatic cholestasis of pregnancy levels of sulfated progesterone metabolites inhibit farnesoid X receptor resulting in a cholestatic phenotype. Hepatology 57: 716-726, 2013.

ABU-HAYYEH S, OVADIA C, LIEU T, JENSEN DD, CHAMBERS J, DIXON PH, LOVGREN-SANDBLOM A, BOLIER R, TOLENAARS D, KREMER AE, SYNGELAKI A, NOORI M, WILLIAMS D, MARIN JJ, MONTE MJ, NICOLAIDES KH, BEUERS U, OUDE-ELFERINK R, SEED PT, CHAPPELL L, MARSCHALL HU, BUNNETT NW, WILLIAMSON C: Prognostic and mechanistic potential of progesterone sulfates in intrahepatic cholestasis of pregnancy and pruritus gravidarum. Hepatology 63: 1287-1298, 2016.

ANAKK S, WATANABE M, OCHSNER SA, MCKENNA NJ, FINEGOLD MJ, MOORE DD: Combined deletion of Fxr and Shp in mice induces Cyp17a1 and results in juvenile onset cholestasis. J Clin Invest 121: 86-95, 2011.

BIASON-LAUBER A, MILLER WL, PANDEY AV, FLUCK CE: Of marsupials and men: "Backdoor" dihydrotestosterone synthesis in male sexual differentiation. Mol Cell Endocrinol 371: 124-132, 2013.

BYRNE JA, STRAUTNIEKS SS, MIELI-VERGANI G, HIGGINS CF, LINTON KJ, THOMPSON RJ: The human bile salt export pump: characterization of substrate specificity and identification of inhibitors. Gastroenterology 123: 1649-1658, 2002.

DUSKOVA M, HILL M, BICIKOVA M, SRAMKOVA M, RIPOVA D, MOHR P, STARKA L: The steroid metabolome in men with mood and anxiety disorders. Physiol Res 64 (Suppl 2): S275-S282, 2015.

ESTIU MC, MONTE MJ, RIVAS L, MOIRON M, GOMEZ-RODRIGUEZ L, RODRIGUEZ-BRAVO T, MARIN JJ, MACIAS RI: Effect of ursodeoxycholic acid treatment on the altered progesterone and bile acid homeostasis in the mother-placenta-foetus trio during cholestasis of pregnancy. Br J Clin Pharmacol 79: 316-329, 2015.

GLANTZ A, REILLY SJ, BENTHIN L, LAMMERT F, MATTSSON LA, MARSCHALL HU: Intrahepatic cholestasis of pregnancy: amelioration of pruritus by UDCA is associated with decreased progesterone disulphates in urine. Hepatology 47: 544-551, 2008.

HILL M, HAMPL R, LUKAC D, LAPCIK O, POUZAR V, SULCOVA J: Elimination of cross-reactivity by addition of an excess of cross-reactant for radioimmunoassay of 17alpha-hydroxypregnenolone. Steroids 64: 341-355, 1999.

HILL M, PARIZEK A, CIBULA D, KANCHEVA R, JIRASEK JE, JIRKOVSKA M, VELIKOVA M, KUBATOVA J, KLIMKOVA M, PASKOVA A, ZIZKA Z, KANCHEVA L, KAZIHNITKOVA H, ZAMRAZILOVA L, STARKA L: Steroid metabolome in fetal and maternal body fluids in human late pregnancy. $J$ Steroid Biochem Mol Biol 122: 114-132, 2010a.

HILL M, PARIZEK A, JIRASEK JE, JIRKOVSKA M, VELIKOVA M, DUSKOVA M, KLIMKOVA M, PASKOVA A, ZIZKA Z, GERMANOVA A, KOUCKY M, KALOUSOVA M, STARKA L: Is maternal progesterone actually independent of the fetal steroids? Physiol Res 59: 211-224, 2010b.

HILL M, PARIZEK A, KANCHEVA R, DUSKOVA M, VELIKOVA M, KRIZ L, KLIMKOVA M, PASKOVA A, ZIZKA Z, MATUCHA P, MELOUN M, STARKA L: Steroid metabolome in plasma from the umbilical artery, umbilical vein, maternal cubital vein and in amniotic fluid in normal and preterm labor. $J$ Steroid Biochem Mol Biol 121: 594-610, 2010c. 
HILL M, PASKOVA A, KANCEVA R, VELIKOVA M, KUBATOVA J, KANCHEVA L, ADAMCOVA K, MIKESOVA M, ZIZKA Z, KOUCKY M, SARAPATKOVA H, KACER V, MATUCHA P, MELOUN M, PARIZEK A: Steroid profiling in pregnancy: a focus on the human fetus. J Steroid Biochem Mol Biol 139: 201-222, 2014.

KAMRATH C, HARTMANN MF, WUDY SA: Androgen synthesis in patients with congenital adrenal hyperplasia due to 21-hydroxylase deficiency. Horm Metab Res 45: 86-91, 2013.

LAMMERT F, MARSCHALL HU, GLANTZ A, MATERN S: Intrahepatic cholestasis of pregnancy: molecular pathogenesis, diagnosis and management. J Hepatol 33: 1012-1021, 2000.

LESLIE KK, REZNIKOV L, SIMON FR, FENNESSEY PV, REYES H, RIBALTA J: Estrogens in intrahepatic cholestasis of pregnancy. Obstet Gynecol 95: 372-376, 2000.

MELOUN M, HILL M, MILITKY J, KUPKA K: Transformation in the PC-aided biochemical data analysis. Clin Chem Lab Med 38: 553-559, 2000.

MELOUN M, MILITKY J, HILL M, BRERETON RG: Crucial problems in regression modelling and their solutions. Analyst 127: 433-450, 2002.

MENG LJ, REYES H, AXELSON M, PALMA J, HERNANDEZ I, RIBALTA J, SJOVALL J: Progesterone metabolites and bile acids in serum of patients with intrahepatic cholestasis of pregnancy: effect of ursodeoxycholic acid therapy. Hepatology 26: 1573-1579, 1997.

MILONA A, OWEN OM, WILLEMSEN EC, WILLIAMSON C, VAN MIL SW: Exploring a role for Cyp17a1 in the pathogenesis of cholestasis. In: XXII International Bile Acid Meeting - Hepatic and Extrahepatic Targets of Bile Acid Signaling. HÄUSSINGER D, BEUERS U, TRAUNER M (eds), Proceedings of Falk Symposium 184, Vienna, 2012, S. Karger AG, Basel, Switzerland, 2013, pp. 65.

PARIZEK A, DUSKOVA M, VITEK L, SRAMKOVA M, HILL M, ADAMCOVA K, SIMJAK P, CERNY A, KORDOVA Z, VRABLIKOVA H, BOUDOVA B, KOUCKY M, MALICKOVA K, STARKA L: The role of steroid hormones in the development of intrahepatic cholestasis of pregnancy. Physiol Res 64 (Suppl 2): S203S209, 2015

PARIZEK A, HILL M, DUSKOVA M, VITEK L, VELIKOVA M, KANCHEVA R, SIMJAK P, KOUCKY M, KOKRDOVA Z, ADAMCOVA K, CERNY A, HAJEK Z, STARKA L: A comprehensive evaluation of steroid metabolism in women with intrahepatic cholestasis of pregnancy. PLoS One 11: e0159203, 2016.

PASCUAL MJ, SERRANO MA, EL-MIR MY, MACIAS RI, JIMENEZ F, MARIN JJ: Relationship between asymptomatic hypercholanaemia of pregnancy and progesterone metabolism. Clin Sci (Lond) 102: 587-593, 2002.

PETRAGLIA F, IMPERATORE A, CHALLIS JR: Neuroendocrine mechanisms in pregnancy and parturition. Endocr Rev 31: 783-816, 2010.

REGE J, KARASHIMA S, LERARIO AM, SMITH JM, AUCHUS RJ, KASA-VUBU JZ, SASANO H, NAKAMURA Y, WHITE PC, RAINEY WE: Age-dependent increases in adrenal cytochrome b5 and serum 5-androstenediol-3-sulfate. J Clin Endocrinol Metab 101: 4585-4593, 2016.

REYES H: Sex hormones and bile acids in intrahepatic cholestasis of pregnancy. Hepatology 47: 376-379, 2008.

REYES H: Sulfated progesterone metabolites in the pathogenesis of intrahepatic cholestasis of pregnancy: another loop in the ascending spiral of medical knowledge. Hepatology 63: 1080-1082, 2016.

RIZZO G, RENGA B, MENCARELLI A, PELLICCIARI R, FIORUCCI S: Role of FXR in regulating bile acid homeostasis and relevance for human diseases. Curr Drug Targets Immune Endocr Metabol Disord 5: 289-303, 2005.

SIMJAK P, PARIZEK A, VITEK L, CERNY A, ADAMCOVA K, KOUCKY M, HILL M, DUSKOVA M, STARKA L: Fetal complications due to intrahepatic cholestasis of pregnancy. J Perinat Med 43: 133-139, 2015.

SIRIANNI R, MAYHEW BA, CARR BR, PARKER CR JR, RAINEY WE: Corticotropin-releasing hormone (CRH) and urocortin act through type $1 \mathrm{CRH}$ receptors to stimulate dehydroepiandrosterone sulfate production in human fetal adrenal cells. J Clin Endocrinol Metab 90: 5393-5400, 2005.

SMITH R, SMITH JI, SHEN X, ENGEL PJ, BOWMAN ME, MCGRATH SA, BISITS AM, MCELDUFF P, GILES WB, SMITH DW: Patterns of plasma corticotropin-releasing hormone, progesterone, estradiol, and estriol change and the onset of human labor. J Clin Endocrinol Metab 94: 2066-2074, 2009. 
STERZL I, HILL M, STARKA L, VELIKOVA M, KANCEVA R, JEMELKOVA J, CZERNEKOVA L, KOSZTYU P, ZADRAZIL J, MATOUSOVIC K, VONDRAK K, RASKA M: Patients with IgA nephropathy have altered levels of immunomodulatory C19 steroids. Glucocorticoid therapy with addition of adrenal androgens may be the choice. Physiol Res 66 (Suppl 3): S433-S442, 2017.

SULCOVA J, HILL M, HAMPL R, STARKA L: Age and sex related differences in serum levels of unconjugated dehydroepiandrosterone and its sulphate in normal subjects. J Endocrinol 154: 57-62, 1997.

VALLEJO M, BRIZ O, SERRANO MA, MONTE MJ, MARIN JJ: Potential role of trans-inhibition of the bile salt export pump by progesterone metabolites in the etiopathogenesis of intrahepatic cholestasis of pregnancy. J Hepatol 44: 1150-1157, 2006.

VANKOVA M, HILL M, VELIKOVA M, VCELAK J, VACINOVA G, LUKASOVA P, VEJRAZKOVA D, DVORAKOVA K, RUSINA R, HOLMEROVA I, JAROLIMOVA E, VANKOVA H, BENDLOVA B: Reduced sulfotransferase SULT2A1 activity in patients with Alzheimer's disease. Physiol Res 64 (Suppl 2): S265-S273, 2015.

VANKOVA M, HILL M, VELIKOVA M, VCELAK J, VACINOVA G, DVORAKOVA K, LUKASOVA P, VEJRAZKOVA D, RUSINA R, HOLMEROVA I, JAROLIMOVA E, VANKOVA H, KANCHEVA R, BENDLOVA B, STARKA L: Preliminary evidence of altered steroidogenesis in women with Alzheimer's disease: have the patients "OLDER" adrenal zona reticularis? J Steroid Biochem Mol Biol 158: 157-177, 2016.

VCELAKOVA H, HILL M, LAPCIK O, PARIZEK A: Determination of 17alpha-hydroxypregnenolone sulfate and its application in diagnostics. Steroids 72: 323-327, 2007.

WANG C, CHEN X, ZHOU SF, LI X: Impaired fetal adrenal function in intrahepatic cholestasis of pregnancy. Med Sci Monit 17: CR265-CR271, 2011.

ZHOU F, HE MM, LIU ZF, ZHANG L, GAO BX, WANG XD: Expression of corticotrophin-releasing hormone and its receptor in patients with intrahepatic cholestasis of pregnancy. Placenta 34: 401-406, 2013. 